\title{
Equivalencia y efectividad en la revisión de los actos administrativos nacionales contrarios al derecho europeo
}

\author{
Jesús Fuentetaja Pastor (España) \\ Universidad Nacional de Educación a Distancia (UNED) \\ jfuentetaja@der.uned.es
}

\section{NOTA BIOGRÁFICA}

Catedrático de Derecho Administrativo (UNED). Sus principales líneas de investigación son el Derecho

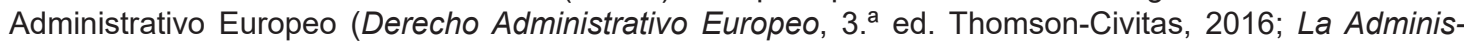
tración europea. La ejecución del Derecho y las Políticas de la Unión, Civitas, 2007) y el Derecho de la Función Pública [Función Pública y Derecho Europeo, Civitas, 2018; Derecho de la Función Pública (junto a R. Parada), Civitas, 2017].

\section{RESUMEN}

Aunque los Estados miembros ejecutan el Derecho de la Unión Europea conforme a su propia normativa, también en relación con la revisión de los actos administrativos que son contrarios a dicho Derecho, los principios ejecutivos europeos de equivalencia y efectividad condicionan el alcance e incluso la aplicación de la regulación nacional de revisión de actos administrativos por la propia Administración o incluso por los Tribunales. Más aún, el Derecho de la Unión puede obligar a los Estados a revisar incluso actos administrativos firmes (en particular cuando el Tribunal Justicia ha esclarecido con posterioridad la interpretación correcta de normas europeas) no sólo cuando su normativa nacional lo prevé (Kühne) sino también cuando el acto administrativo nacional vulnera gravemente la norma europea aún no existiendo procedimiento para revisar dicho acto incluso firme (Byankov).

\section{PALABRAS CLAVE}

Principio de equivalencia; principio de efectividad; acto administrativo contrario al derecho europeo.

\begin{abstract}
Although member states implement EU Law in accordance to their procedural law, also in relation to the review of administrative decisions that are contrary to that Law, the European executive principles of equivalence and effectiveness condition the scope and even the application of the national regulation of review of administrative acts by the Administration itself or even by the Courts. In particular, Member States may be even forced to reopen a final decisions -in particular to take account of the interpretation of a relevant provision of European law which the Court has given subsequently- not only if they have te power to do so (Kühne) but also because of the gravity of the infringement of EU Law and requiring Administration to reopen final decisions precluding national legislation that makes no provision for regular review (Byankov).
\end{abstract}

\section{KEYWORDS}

Principle of equivalence; principle of effectiveness; administrative act contrary to european law.

\section{SUMARIO}

I. EJECUCIÓN DEL DERECHO EUROPEO Y ADMINISTRACIÓN NACIONAL. 1. PRINCIPIOS EJECUTIVOS EUROPEOS Y SISTEMA INTERNO DE REVISIÓN DE ACTOS. 2. COLISIONES Y CONTRADIC- 
CIONES CON EL DERECHO EUROPEO. II. PRINCIPIO DE EQUIVALENCIA Y VALIDEZ Y REVISIÓN INTERNA. III. PRINCIPIO DE EFECTIVIDAD Y REVISIÓN DE ACTOS NACIONALES CONTRARIOS AL DERECHO EUROPEO. 1. CONCEPTO Y ALCANCE DEL PRINCIPIO DE EFECTIVIDAD. 2. EFECTIVIDAD Y CATEGORIZACIÓN DE INVALIDEZ. 3. EFECTIVIDAD Y PROCEDIMIENTOS DE REVISIÓN. 3.1. OBLIGACIÓN DE REVISIÓN DE ACTOS FIRMES CONFORME A PROCEDIMIENTOS INTERNOS. 3.2. DERECHO A UN PROCEDIMIENTO DE REVISIÓN POR VULNERACIÓN DEL DERECHO EUROPEO. 4. EFECTIVIDAD Y EFECTOS DE LA REVISIÓN. IV. CONCLUSIONES.

\section{EJECUCIÓN DEL DERECHO EUROPEO Y ADMINISTRACIÓN NACIONAL}

\section{Principios ejecutivos europeos y sistema interno de revisión de actos}

En el marco de la ejecución indirecta del Derecho europeo, según la cual la titularidad ejecutiva corresponde a los Estados miembros, las Administraciones nacionales dictan reglamentos y actos administrativos de aplicación de aquel. En el caso de que estos actos -que aplican el Derecho europeo pero que se dictan también conforme al Ordenamiento jurídico-administrativo interno- vulnerasen el Ordenamiento europeo, éste exige de los Estados que reaccionen para garantizar la legalidad europea quebrantada.

Por tanto, los Estados no sólo son responsables del cumplimiento del Derecho europeo sino también de su incumplimiento. Esto es, de prever y activar mecanismos jurídicos para restablecer la legalidad europea vulnerada por la acción administrativa nacional.

En caso de incumplimiento del Derecho europeo, tanto en el ámbito nacional como en el europeo, aquel contempla principalmente cuatro tipos de medidas. En primer lugar, las sanciones ${ }^{1}$, que el Derecho europeo sectorial (agricultura, fondos europeos, etc.) o especial (por ejemplo, protección de intereses financieros) puede prever para reprimir y disuadir a los incumplidores por su incumplimiento. En segundo lugar, procedimientos ejecutivos para declarar la irregularidad del uso de fondos europeos (por ejemplo, las liquidaciones de conformidad en el ámbito de la $\mathrm{PAC}^{2}$ o las correcciones financieras de los fondos estructurales ${ }^{3}$ ). En tercer lugar, en caso de incumplimiento del Derecho europeo, surgiría la responsabilidad de la Unión o de los Estados, según el caso. Y, en cuarto lugar, cuando la legalidad europea sea quebrantada por normas y actos administrativos, se deberán establecer mecanismos de reacción adecuados para restablecer aquella legalidad.

Este restablecimiento de la legalidad europea vulnerada por normas o actos administrativos nacionales, puede venir determinado bien en normas europeas ( $v$. gr. las muy precisas previsiones del Código Aduanero ${ }^{4}$ ), bien en normas nacionales expresa y específicamente aprobadas para garantizar la legalidad europea (v. gr. la previsión de un supuesto de nulidad de pleno derecho de los contratos administrativos declarados expresamente contrarios al Derecho europeo por el Tribunal de Justicia de la Unión Europea). En el caso de que ni el Derecho europeo ni el nacional prevean una respuesta expresa a la restitución de la legalidad europea vulnerada, el Ordenamiento europeo se remite al sistema de garantía interna de la legalidad nacional de que disponen los Estados miembros (principio de autonomía institucional). Por tanto, el sistema nacional de invalidez y revisión de los actos administrativos nacionales se deberá aplicar en las mismas condiciones cuando esos actos administrativos nacionales vulneran el Derecho europeo (principio de equivalencia), si bien este Derecho -que, no se olvide, es el vulnerado- puede exigir correcciones al sistema interno de invalidez y de revisión si considera que la configuración de dicho sistema no responde adecuadamente a vulneración de la legalidad europea (principio de efectividad).

De lo dicho se deduce que el régimen jurídico de la validez y revisión de los actos administrativos nacionales que vulneran el Derecho europeo no constituye un sistema previamente diseñado y regulado ni por el Legislador europeo ni por el Legislador nacional sino que se limita más bien a dar cuenta de la incidencia

\footnotetext{
1 Imprescindible el estudio de LOPEZ BENITEZ, M. (2008): "Marco institucional de las sanciones comunitarias", en Documentación Administrativa, núm. 280-281.

2 BUENO ARMIJO, A. (2013): "Una alternativa al procedimiento de incumplimiento: las correcciones financieras de la política agrícola común”, en Revista Española de Derecho Europeo, núm. 46, págs. 29-75.

3 GUILLEM CARRAU, J. (2018): "Las correcciones financieras en materia de fondos estructurales", en Revista Aragonesa de Administración Pública, núm. 51, págs. 281-319.

${ }_{4}^{4}$ Reglamento (952/2013/UE) del Parlamento Europeo y del Consejo, de 9 de octubre de 2013 (DO núm. L 269 de 10 de octubre de 2013, pág. 1).
} 
puntual, de carácter normativo y sobre todo jurisprudencial, de las exigencias del Derecho europeo para asegurarse que el sistema de validez y revisión interno es aplicado indistintamente respecto a actos internos y eficazmente respecto a la legalidad europea.

\section{Colisiones y contradicciones con el Derecho europeo}

Además de lo señalado respecto a los principios ejecutivos europeos como correctores de la autonomía nacional a la hora de aplicar el Derecho europeo y, en particular, por su afectación al sistema de garantía de la legalidad por los actos administrativos, es preciso señalar que al estudiar la temática relativa a la invalidez y revisión de los actos administrativos nacionales que vulneran el Derecho europeo nos encontramos no sólo con contradicciones entre dicho acto nacional y el Derecho europeo sino también con inadecuaciones o colisiones entre el sistema de ejecución (procedimientos administrativos de revisión, fundamentalmente) y la garantía de la efectividad de aquel Derecho. A su vez, la contradicción del acto administrativo puede ser directa (si es el propio acto el que contraviene la norma europea) o indirecta (si la vulneración de esta norma europea no es del acto sino de la norma europea o nacional de la que el acto administrativo nacional es aplicación).

En el caso de las contradicciones indirectas, el escenario es aún más complejo, pues es preciso distinguir las normas de las que puede ser aplicación el acto, por lo que la derivación de consecuencias de la nulidad de aquellas sobre éste va a depender decisivamente en función de que la norma sea interna o que la norma sea europea. En el primer caso, será preciso, asimismo, distinguir si se trata de una ley (que no podrá ser anulada porque la infracción del Derecho europeo no determinada su inconstitucionalidad, sino su inaplicación) o de un reglamento (que sí podrá ser anulada). Mientras que en el caso de las normas europeas que son declaradas nulas por el Tribunal de Justicia, las consecuencias sobre los actos administrativos nacionales de aplicación vendrán asimismo condicionadas por el propio Derecho europeo. Más aún, es el propio Tribunal de Justicia el que puede modular los efectos en el tiempo no sólo de la anulación de la norma europea de la que es aplicación el acto administrativo nacional, sino también de los de la declaración de no conformidad con el Derecho europeo de las normas nacionales a través de recursos de incumplimiento o cuestiones prejudiciales ${ }^{5}$.

Todos estos escenarios deben ser tenidos en cuenta, pues implican a su vez la intervención de elementos que inciden decisivamente en la materia, como puede ser la eficacia y alcance de sentencias del Tribunal de Justicia que declaren la contradicción de normas europeas o nacionales con el Derecho europeo ${ }^{6}$.

\section{PRINCIPIO DE EQUIVALENCIA Y VALIDEZ Y REVISIÓN INTERNA}

Siempre que no exista regulación europea sobre la ejecución del Derecho de la Unión o normativa nacional específica que establezca el régimen jurídico interno de dicha ejecución, el principio de equivalencia exigirá que se aplique a la ejecución del Derecho europeo el Derecho nacional establecido con carácter general para regular la ejecución del Derecho interno. Se trata, por tanto, de aplicar normativa interna reguladora de supuestos internos a supuestos europeos. Así, por ejemplo, si la normativa interna

\footnotetext{
${ }^{5}$ Así lo hizo el Tribunal de Justicia, por ejemplo, al declarar nulo el Reglamento (2772/1999/CE) del Consejo, por el que se aprobaron las normas generales de un sistema obligatorio de etiquetado de la carne de vacuno, pues consideró que su anulación podría crear un vacío jurídico que habría permitido, en particular, impugnar las decisiones que hubieran podido adoptar los Estados miembros. De ahí que, por razones de seguridad jurídica, resolvió «considerar definitivos los efectos de lo dispuesto en el Reglamento impugnado, para cuya ejecución los Estados miembros han podido adoptar decisiones que podrían ser recurridas»: Parlamento v. Consejo, 13 diciembre 2001 (C-93/00), Rec., pág. I-10119, núm. 48. También lo hizo en relación con la anulación del artículo 7 del Reglamento (1308/2013/UE) del Parlamento Europeo y del Consejo, de 17 de diciembre de 2013, por el que se crea la organización común de mercados de los productos agrarios que, en tanto en cuanto fija los precios a los que debe realizarse la intervención pública y por tanto se encamina a estabilizar los mercados agrícolas, no sólo limitó retroactivamente sus efectos sino también hacia el futuro, otorgando al Legislador un plazo de cinco meses para adoptar una nueva normativa. Alemania v. Parlamento y Consejo, 7 septiembre 2016 (C113/14), núm. 84. Otro relevante ejemplo de mantenimiento de efectos del acto anulado hacia el futuro lo encontramos en Borealis Polyolefine, 28 abril 2016 (C-191/14, C-192/14, C-295/14, C-389/14 et C-391/14 à C-393/14), que anulaba con efectos diferidos a diez meses la Decisión (2013/448/UE) de la Comisión, de 5 de septiembre de 2013, relativa a las medidas nacionales de aplicación para la asignación gratuita transitoria de derechos de emisión de gases de efecto invernadero.

6 Vid., al respecto, el excelente trabajo de NUÑEZ LOZANO, C. (2017): "La eficacia de las sentencias del Tribunal de Justicia de la Unión Europea sobre los Actos Nacionales", en El alcance de la invalidez de la actuación administrativa: Actas del XII Congreso de la Asociación Española de Profesores de Derecho Administrativo, págs. 549-614.
} 
considera que un reglamento que vulnera una norma superior interna (Constitución o Ley, por ejemplo) debe ser declarado nulo de pleno derecho, la misma solución habrá que dar cuando el reglamento vulnera el Derecho europeo, careciendo de fundamento trasladar a este supuesto la consecuencia de la contradicción de leyes en forma de inaplicación ${ }^{7}$.

Pero a lo que no obliga el principio de equivalencia es a aplicar normativa interna reguladora de supuestos europeos de ejecución a otros supuestos europeos. Así, cuando la Ley 9/2017, de 8 de noviembre, de Contratos del Sector Público tipifica como causa de nulidad de pleno derecho «[e]l incumplimiento grave de normas de derecho de la Unión Europea en materia de contratación pública que conllevara que el contrato no hubiera debido adjudicarse al contratista, declarado por el TJUE en un procedimiento con arreglo al artículo 260 del Tratado de Funcionamiento de la Unión Europea», constituye una norma interna finalizada a prever las consecuencias de la vulneración del Derecho europeo. Pero al tratarse de una norma interna reguladora de una consecuencia de incumplimiento del Derecho europeo, el principio de equivalencia no exige que se aplica a otros supuestos pretendidamente semejantes en caso de incumplimiento. Por ejemplo, un incumplimiento grave del Derecho europeo en materia de fondos europeos concedidos mediante subvención competitiva que conllevara que ésta no hubiera debido adjudicarse al beneficiario, declarado por el TJUE en el marco de un recurso por incumplimiento, no cabría categorizarse como supuesto de nulidad de pleno derecho de la subvención por equivalencia con la previsión positivizada en la normativa de contratos.

Cuestión diferente es que esa extensión aplicativa se llevara a cabo no por exigencia del principio europeo de equivalencia sino por mor de una interpretación analógica de la norma interna, optimizando al máximo la interpretación conforme del Ordenamiento nacional para garantizar la efectividad del Derecho europeo, que en este caso supondría apurar las posibilidades de apreciación de la semejanza de situaciones, que en última instancia es el talón de Aquiles del juicio analógico. De esta forma, cuando la Ley General de Subvenciones establece en su artículo $37.1 \mathrm{~h}$ ) que será causa de reintegro de una subvención la declaración por la Comisión europea de que una ayuda de Estado canalizada a través de aquella es ilegal, al amparo de los artículos 87 a 89 del TFUE, está tipificando específicamente una previsión especial de ejecución del Derecho europeo por contradicción de un acto interno -la subvención- con el Derecho europeo de la Competencia. Pero esta norma interna no se debe extender y aplicar, en virtud del principio de equivalencia, a supuestos semejantes; sin embargo, podría hacerse esa extensión por analogía a supuestos donde la Comisión también declara en procedimientos administrativos que ciertas actuaciones de las Administraciones - plasmadas en actos administrativos- son contrarias al Derecho europeo. Como las declaraciones que hace la Comisión, en el marco de procedimientos de corrección financiera de los Fondos estructurales o de liquidaciones de conformidad de la Política Agrícola Común, según las cuales se han utilizado fondos europeos contraviniendo la norma sectorial europea reguladora del uso de dichos fondos.

En virtud del principio de equivalencia, se debe proceder pues a la aplicación indiferenciada de la norma nacional a los procedimientos basados en el Derecho de la Unión y a los basados en el Derecho nacional ${ }^{8}$. Por tanto, el sistema procedimental y procesal nacional se debe aplicar indistintamente a los recursos basados en la violación del Derecho europeo y a aquellos basados en la infracción del Derecho interno ${ }^{9}$, comprendiendo todos los aspectos de dicho sistema: desde los plazos para el ejercicio de acciones o interposición de recursos ${ }^{10}$ a las facultades del juez ${ }^{11}$, pasando por los requisitos para la interposición de los recursos.

7 Por ejemplo, la STS de 7 de febrero de 2012, tras constatar la contradicción con el Derecho europeo del Real Decreto-ley $6 / 2009$, de 30 de abril, por el que se adoptan determinadas medidas en el sector energético y se aprueba el bono social, lo declara inaplicable, y traslada esa solución a una Orden ministerial que desarrollaba y aplicaba aquel. No obstante, los Tribunales hoy día declaran sin mayores titubeos la nulidad de pleno derecho de reglamentos contrarios al Derecho europeo, también cuando son desarrollo de leyes inaplicadas por su contradicción con aquel. Por ejemplo, A la luz de la Sentencia del TJUE Entidad de Gestión de Derechos de los Productores Audiovisuales (EGEDA) e.a., 9 junio 2016 (C-470/14). el Tribunal Supremo concluye la incompatibilidad del Real Decreto-ley 20/2011 y de la Ley 21/2014 que modifica el Texto Refundido de la Ley de Propiedad Intelectual con la Directiva 2001/29/ CE relativa a la armonización de determinados aspectos de los derechos de autor y derechos afines a los derechos de autor en la sociedad de la información. En la medida en que el Real Decreto 1657/2012, de 7 de diciembre, por el que se regula el procedimiento de pago de la compensación equitativa por copia privada con cargo a los Presupuestos Generales del Estado, había sido dictado para ejecución de esas normas con rango de ley, la Sentencia considera que el mismo ha quedado sin «fundamento legal efectivo y, en consecuencia, es nulo».

8 ÖBB Personenverkehr, 28 enero 2015 (C417/13), núm. 74.

9 i-21 y Arcor, 19 septiembre 2006 (C-392/04 y C-422/04), núm. 62.

10 Rosado Santana, 8 septiembre 2011 (C-177/10), en relación con los recursos previstos en la ley de procedimiento administrativo española.

11 «Si bien el Derecho comunitario no obliga a los órganos jurisdiccionales nacionales a examinar de oficio un motivo basado en la infracción de disposiciones de la normativa comunitaria cuando el examen de dicho motivo las obligaría a exceder los límites del 
Sin embargo, el principio de equivalencia no obliga a establecer regulaciones internas comunes a efectos de su aplicación al Derecho europeo, pudiéndose, por ejemplo, distinguir plazos de ejercicio de acciones diferenciando el sector privado y el sector público ${ }^{12} \mathrm{o}$ una regulación procesal diversa para la jurisdicción civil y para la jurisdicción contencioso-administrativa ${ }^{13}$. Y tampoco permite elegir la modalidad más favorable de entre las existentes, violentando la regulación positiva ${ }^{14}$. Finalmente, tampoco es pertinente en situaciones que afectan a dos clases de acciones basadas ambas en una infracción del Derecho europeo ${ }^{15}$.

En relación con la temática de la invalidez y revisión de los actos administrativos contrarios al Derecho europeo, el principio de equivalencia exige la aplicación tanto de las mismas categorías sustantivas internas de invalidez según los vicios del acto como de las mismas técnicas de revisión previstas en la normativa nacional para los casos internos.

Sin embargo, en el contraste entre al acto administrativo nacional y el Derecho europeo potencialmente vulnerado es imprescindible tener en cuenta que el contenido y alcance de la norma europea viene determinado por el propio Ordenamiento europeo, no por el interno, pudiéndose dar incluso el caso de que el Tribunal de Justicia interprete normativa nacional al analizar si el acto nacional vulnera y en qué grado la norma europea. Lo cual tiene una gran trascendencia a la hora de aplicar, por ejemplo, los supuestos de nulidad de pleno derecho.

En efecto, la aplicación de las categorías internas de invalidez, con sus causas respectivas, debe hacerse sobre la base del principio de equivalencia, de manera que el supuesto de hecho se subsuma en una de ellas con independencia de que la norma infringida sea europea, aplicando la misma categoría de invalidez a las mismas vulneraciones del Derecho, sea éste nacional, sea europeo. Ahora bien, la interpretación del Derecho europeo en cada caso debe realizarse teniendo en cuenta su contenido y alcance, en particular conforme a la jurisprudencia del Tribunal de Justicia. Pero también el principio de equivalencia exigirá que los Tribunales europeos interpreten la norma nacional, sólo así podrá valorar si el juicio de semejanza propio de la equivalencia se ha realizado correctamente, así como si la causa de invalidez tipificada en el Derecho nacional se ha aplicado de forma adecuada a la concreta infracción del Derecho europeo. La sentencia i-21 y $\operatorname{Arcor}^{16}$ da una buena idea de ello, cuando el Tribunal de Justicia analizó si la vulneración de la norma europea en cuestión constituía una "violación manifiesta» a efectos de la Ley de procedimiento administrativa alemana que obligara a revisar un acto administrativo firme.

El contenido y el alcance de las normas europeas presentan una particular relevancia en algunas de las causas de invalidez que determinan la nulidad de pleno Derecho del acto. Es el caso de los vicios procedimentales y de la vulneración de los derechos fundamentales.

Respecto a la cuestión del alcance de los vicios de procedimiento a efectos de determinar, por un lado, la invalidez o no de un acto y, por otro y en su caso, la categoría concreta de invalidez (nulidad o anulabilidad, en el caso español), se trata un problema constante en todo Ordenamiento jurídico. El Derecho europeo no es una excepción, ni cuando se trata de controlar sus propios actos ni cuando valora la importancia de las previsiones organizativas y procedimentales que impone a los Estados cuando ejecutan Derecho europeo.

litigio tal como lo habían delimitado las partes, dichos órganos jurisdiccionales deben examinar de oficio los fundamentos de Derecho basados en una norma comunitaria de carácter imperativo cuando, en virtud del Derecho nacional, estén obligadas o facultadas para hacerlo en el caso de una norma de Derecho interno de carácter imperativo»: Van Schijndel y van Veen, 14 diciembre 1995 (C-430/93 y C-431/93), Rec. pág. I-4705, núms. 13, 14 y 22 y Kraaijeveld e.a., 24 octubre 1996 (C-72/95), Rec. pág. I-5403, núms. 57, 58 y 60.

12 Ministero delle Finanze v. Spac, 15 septiembre 1998 (C-260/96), Rec. pág. I-4997, núms. 18-23: El principio de equivalencia «no puede interpretarse en el sentido de que obliga a un Estado miembro a extender a todas las acciones de devolución de tributos o exacciones percibidos en contra de las disposiciones del Derecho comunitario su régimen de repetición interno más favorable. Así pues, el Derecho comunitario no se opone a que la legislación de un Estado miembro contemple, junto a un plazo de prescripción de Derecho común aplicable a las acciones de repetición de lo indebido entre particulares, procedimientos específicos de reclamación y de recurso judicial menos favorables para la impugnación de los tributos y demás exacciones. Sólo cabría una solución distinta si dichos procedimientos fueran aplicables única y exclusivamente a las acciones de devolución de tributos o exacciones basadas en el Derecho comunitario».

13 Târșia, 6 octubre 2015 (C-69/14), núm. 35: «el principio de equivalencia no se opone a que un juez nacional no tenga la posibilidad de revisar una resolución judicial firme dictada en un procedimiento civil, cuando esta resolución resulta incompatible con una interpretación del Derecho de la Unión adoptada por el Tribunal de Justicia con posterioridad a la fecha en la que dicha resolución ha devenido firme, mientras que tal posibilidad existe en lo que atañe a las resoluciones judiciales firmes incompatibles con el Derecho de la Unión dictadas en el marco de procedimientos administrativos».

14 Ministero delle Finanze v. Spac, 15 septiembre 1998 (C-260/96), Rec. pág. I-4997, núm. 18; Dragoș Constantin Târșia, 6 octubre 2015 (C-69/14), núm. 35.

15 ÖBB Personenverkehr AG, 28 enero 2015 (C-417/13), núm. 74.

16 I-21 y Arcor, 19 septiembre 2006 (C-392/04 y C-422/04). 
Así, por ejemplo, el Tribunal de Justicia considera que un vicio de procedimiento no exige la anulación de la decisión impugnada si al tribunal le es posible concluir - sin imponer en absoluto al demandante la carga de la prueba a este respecto, sino tomando en consideración, en su caso, los elementos de prueba aportados por el promotor del proyecto o por las autoridades competentes y, más generalmente, el conjunto de los documentos del asunto que se le haya sometido-que la decisión impugnada no habría sido diferente sin el vicio de procedimiento invocado por el demandante ${ }^{17}$.

Con esto se quiere indicar que el alcance invalidante de un vicio de procedimiento dependerá de la importancia que el propio Ordenamiento europeo dé al procedimiento vulnerado, no de cómo el Ordenamiento nacional considere esa violación. Aunque, obviamente, si la propia norma europea que establece el procedimiento o el Tribunal de Justicia al interpretarla no han calificado como esencial el trámite en cuestión, será el Derecho interno y los Tribunales nacionales, precisamente en virtud del principio de equivalencia, quienes apliquen su concepción interna de los vicios de procedimiento a los supuestos europeos.

Otro tanto sucede con la causa de nulidad de pleno derecho consistente en la lesión de «los derechos y libertades susceptibles de amparo constitucional» [art. 47.1 a) LPAC]. Conforme al principio de equivalencia, sólo la vulneración de los derechos y libertades recogidos en la Carta de Derechos Fundamentales que se correspondan con los susceptibles de amparo constitucional en el Derecho español podrá ser calificada como causa de nulidad de pleno derecho. Pero el contenido y el alcance de esos derechos será el que establezca el Tribunal de Justicia para considerar así que los derechos europeos han sido vulnerados por un acto nacional ${ }^{18}$.

Más aún, cabría cuestionarse si esa delimitación interna de los derechos y libertades cuya violación por un acto determina la mayor categorización invalidante en el ámbito interno responde a la valoración de los derechos y libertades en el Ordenamiento europeo. Además de esta dimensión sustantiva de la vulneración de derechos y libertades fundamentales, es preciso mencionar la procesal, pues si el criterio del amparo restringiría, obviamente, los derechos de la Carta de Derechos Fundamentales cuya vulneración permitiría calificarse internamente como nulidad de pleno derecho. Sin embargo, hay que tener en cuenta que esa equivalencia entre los derechos constitucionales susceptibles de amparo constitucional y los correspondientes de la Carta de Derechos Fundamentales de la Unión Europea no permite, en cambio, que éstos tengan acceso por sí mismos al Tribunal Constitucional, pues éste se considera sólo garante de los primeros. Sólo en la medida en que la vulneración de un derecho fundamental de la Unión Europea constituya al tiempo una vulneración de un derecho constitucional susceptible de amparo, será posible acceder a esta vía si un acto administrativo nacional vulnera un derecho europeo ${ }^{19}$.

El problema práctico sólo se planteará cuando el alcance de los derechos constitucionales susceptibles de amparo y el de los equivalentes de la Carta no sean coextensos, cosa que el Tribunal Constitucional parece querer evitar, como demuestra la STC 26/2014, de 13 de febrero («Melloni»), aun a riesgo de rebajar el nivel de protección interno de los derechos ${ }^{20}$. Pero desde un punto de vista teórico, cabe dudar de que la interpretación del Tribunal Constitucional de que la vulneración de un derecho europeo -de los que por semejanza serían susceptibles de amparo interno- no basta por sí misma para acceder al Tribunal Constitucional a través del recurso resulte conforme con el principio de equivalencia ${ }^{21}$.

17 Gemeinde Altrip e.a, 7 noviembre 2013 (C72/12), núm. 53, y Comisión v. Alemania, 15 octubre 2015 (C137/14), núm. 60.

18 La problemática del alcance de los derechos fundamentales en la Unión Europea se expone con claridad en MUÑOZ MACHADO, S. (2015): "Los tres niveles de garantías de los derechos fundamentales en la Unión Europea: problemas de articulación", en Revista de Derecho Comunitario Europeo, año 19, núm. 50, págs. 195-230.

19 Recuérdese la doctrina asentada por el Tribunal Constitucional ya desde su Sentencia 64/1991, de 22 de marzo, según la cual «los motivos de amparo han de consistir siempre en lesiones de los derechos fundamentales y libertades públicas enunciadas en los arts. 14 a 30 C. E. [arts. 53.2 y 161.1 b), C. E. y Título III LOTC], con exclusión, por tanto, de las eventuales vulneraciones del Derecho comunitario, cuyas normas, además de contar con específicos medios de tutela, únicamente podrían llegar a tener, en su caso, el valor interpretativo que a los Tratados internacionales asigna el art. 10.2 C. E. Consecuentemente, el único canon admisible para resolver las demandas de amparo es el del precepto constitucional que proclama el derecho o libertad cuya infracción se denuncia, siendo las normas comunitarias relativas a las materias sobre las que incide la disposición o el acto recurrido en amparo un elemento más para verificar la consistencia o inconsistencia de aquella infracción, lo mismo que sucede con la legislación interna en las materias ajenas a la competencia de la Comunidad». Concluyendo que «en la medida en que se impugne en amparo un acto del poder público que, habiendo sido dictado en ejecución del Derecho Comunitario europeo, pudiera lesionar un derecho fundamental, el conocimiento de tal pretensión corresponde a esta jurisdicción constitucional con independencia de si aquel acto es o no regular desde la estricta perspectiva del ordenamiento comunitario europeo y sin perjuicio del valor que éste tenga a los efectos de lo dispuesto en el art. $10.2 \mathrm{C}$. E.».

${ }_{20}$ Crítico con esta Sentencia ALONSO GARCÍA, R. (2014a): El juez nacional en la encrucijada europea de los derechos fundamentales, Pamplona: Civitas.

21 En idéntico sentido ARZOZ SANTISTEBAN, X. (2015): La tutela de los derechos fundamentales de la Unión Europea por el Tribunal Constitucional, Madrid: Instituto Nacional de Administración Pública, pág. 115. 


\section{PRINCIPIO DE EFECTIVIDAD Y REVISIÓN DE ACTOS NACIONALES CONTRARIOS AL DERECHO EUROPEO}

Ahora bien, el principio de equivalencia es necesario pero puede no ser suficiente para el Derecho europeo. Recurrir instrumentalmente a la normativa nacional correspondiente puede no garantizar el respecto formal y material de la norma europea según sea la finalidad de ésta. De ahí la necesidad de un ulterior principio corrector, que sería el de efectividad. Y es que el principio de equivalencia no deja de ser un criterio o estándar mínimo de protección o defensa del Derecho europeo en su fase de ejecución. Utilizar los mecanismos procedimentales de ejecución nacional sólo es conveniente en la medida en que se adecúen a la regulación sustantiva europea, lo que en ocasiones puede llevar a proceder a esa adecuación con el objetivo de alcanzar la máxima efectividad de aquella regulación sustantiva mediante interpretaciones de conformidad que optimicen la regulación ejecutiva nacional. Es aquí cuando entra en juego el principio de efectividad, que sin duda es el que va a afectar de manera más trascendente al sistema interno de revisión de actos contrarios al Derecho europeo.

\section{Concepto y alcance del principio de efectividad ${ }^{22}$}

El principio de efectividad exige que aquella normativa nacional ni impida ni dificulte excesivamente la eficacia del Derecho europeo. A tal fin, el principio de efectividad exige la máxima potenciación del principio de interpretación conforme para que se pueda extraer del conjunto del Ordenamiento nacional la modalidad ejecutiva más adecuada para obtener los resultados perseguidos por el acto europeo. Y con más alcance aún que en el ámbito del principio de equivalencia, el Tribunal de Justicia procederá a interpretar el Derecho nacional para proporcionar a los Jueces nacionales parámetros desde los cuales no ya cohonestar las eventuales contradicciones entre ambos Ordenamientos ${ }^{23}$ sino incluso identificar la solución aplicativa interna que permita a la norma nacional desplegar efectos de la mejor manera posible.

Se trata, por ello, de un principio de resultados, que obliga a identificar en qué consiste esa eficacia del Derecho europeo, pues su contenido variará en función del objeto de éste, según los objetivos que pretende conseguir cada disposición del Ordenamiento europeo que debe ser ejecutada por los Estados miembros, ya se trate del ejercicio por los ciudadanos de un derecho reconocido por el Ordenamiento europeo ${ }^{24}$, ya de la consecución de objetivos de las Políticas europeas, como garantizar la competencia efectiva entre empresas (lo que obliga a recuperar las ayudas de Estado ilegales concedidas ${ }^{25} \mathrm{o}$ a no obstaculizar la liberalización de un sector ${ }^{26}$ ), ya del correcto uso del presupuesto europeo garantizando la recuperación de fondos incorrectamente utilizados ${ }^{27}$.

Al concebirse como un principio de resultados, del principio de efectividad, se derivaría la consecuencia de reconocer a los Jueces y Tribunales, una vez concluido -implícita o explícitamente- que una norma procedimental nacional impide o dificulta excesivamente a la disposición europea desplegar sus efectos, la facultad de adoptar decisiones positivas que permitan la eficacia del acto europeo. Esta aproximación positiva al papel de los Jueces y Tribunales ha terminado por erigirse en un corolario autónomo del principio de efectividad, consagrando el principio de tutela judicial efectiva. A partir de aquí, el principio de efectividad se

22 Vid. SARMIENTO, D. (2016): El Derecho de la Unión Europea, Marcial Pons, págs. 424-429.

23 Por ejemplo, en Klausner, 11 noviembre 2015 (C-505/14), en un asunto en el que un Tribunal alemán, tras comprobar que unos contratos de suministro de madera entre la Administración forestal y unas empresas constituían ayudas de Estado ejecutadas infringiendo el art. 108 TFUE, consideraba que la aplicación de una norma de Derecho nacional que tiene la finalidad de consagrar el principio de cosa juzgada le impedía extraer todas las consecuencias de esa infracción debido a la existencia de una resolución judicial nacional firme que, sin examinar si dichos contratos establecen una ayuda de Estado, declaró que éstos siguen en vigor, el Tribunal de Justicia señaló que, «aunque el órgano jurisdiccional remitente haya considerado que las excepciones al principio de cosa juzgada previstas en el Derecho procesal civil alemán no son aplicables en el presente litigio, es preciso indicar que, en virtud del artículo 322 , apartado 1 , de la ZPO, una sentencia sólo adquirirá fuerza de cosa juzgada material en la medida en que se haya pronunciado sobre la pretensión formulada en la demanda o en la reconvención. Corresponde al juez remitente comprobar si dicho límite, expresamente mencionado en el artículo 322 de la ZPO, no le autoriza a interpretar esa disposición en el sentido de que cuando se alega una infracción del artículo 108 TFUE, apartado 3, tercera frase, la fuerza de cosa juzgada únicamente se extiende a las pretensiones jurídicas sobre las que se haya pronunciado el tribunal y, por lo tanto, no obsta a que un juez se pronuncie, en el marco de un litigio posterior, sobre cuestiones jurídicas respecto a las que la sentencia firme no se haya pronunciado».

24 Byankov, 4 octubre 2012 (C-249/11), que afectaba a la libre circulación de personas y a la libertad de establecimiento.

25 Italia v. Comisión, 7 marzo 2002 (C-310/99), Rec., pág. I-2289.

26 i-21 y Arcor, 19 septiembre 2006 (C-392/04 y C-422/04), núm. 70.

27 Países Bajos v. Comisión, 14 abril 2011 (T-70/09), núms. 47-49. 
ha aplicado para verificar la adecuación de múltiples aspectos organizativos y procedimentales de los Derechos nacionales, que abarcan desde los plazos para ejercer acciones o interponer recursos a las potestades de Jueces y Tribunales (por ejemplo, ampliando el objeto del proceso ${ }^{28}$ o permitiendo la anulación retroactiva de actos administrativos ${ }^{29}$ ), pasando por los vicios que se pueden invocar al interponer recursos ${ }^{30} \mathrm{o}$ la revisión de actos administrativos firmes o que se benefician del principio de la cosa juzgada.

Sin embargo, el fin de la plena efectividad del Derecho europeo no justifica cualquier conclusión a la que se pueda llegar en virtud del «test de efectividad» al que se somete el Derecho nacional. Y es que, de la mentada caracterización del principio de efectividad como principio de resultados y de su aplicación por los Tribunales europeos y nacionales, se deriva una de sus consecuencias más criticadas: su potencialidad impredecible. En efecto, la comprensión radical del principio de efectividad podría abocar al cuestionamiento continuo del Derecho nacional, cuando no a su vaciamiento práctico, propiciando interpretaciones de conformidad que desbordan la legalidad positiva.

Un buen ejemplo de ello lo observamos en el caso de las consecuencias que se deben aplicar tras la constatación de nombramiento fraudulentos de funcionarios interinos por su duración absoluta (excesiva duración) o relativa (encadenamientos repetitivos), los cuales vulnerarían la Directiva 1999/70/CE del Consejo, de 28 de junio de 1999, relativa al Acuerdo marco de la CES, la UNICE y el CEEP sobre el trabajo de duración determinada. El Ordenamiento español no ha previsto consecuencia alguna específica a tales supuestos, a diferencia de los casos en que el encadenamiento abusivo de contrataciones temporales afecta a personal laboral, para los cuales, en el ámbito de las Administraciones Públicas, se ha engendrado jurisprudencialmente el concepto de los «indefinidos no fijos». Pues bien, el Tribunal de Justicia no sólo constata el incumplimiento de la normativa española al no establecer medidas para prevenir y sancionar el abuso de nombramientos temporales encadenados sino que advierte a los Tribunales que, para alcanzar el objetivo pretendido por la Directiva, podrían aplicar a los empleados temporales de naturaleza administrativa lo que se aplica a los empleados temporales de naturaleza laboral, es decir, la transformación en indefinida de los nombramientos ${ }^{31}$, algo completamente inédito en la normativa de Función Pública española ${ }^{32}$. El Tribunal Supremo, en cambio, no ha admitido tal posibilidad y ha reconducido la solución a la propia normativa de Función Pública, considerando nulos los ceses del personal objeto de abuso por ausencia de causa válida, teniendo sólo por tales la provisión reglamentaria de la plaza o su amortización ${ }^{33}$.

\section{Efectividad y categorización de invalidez}

Dicho lo cual, y desde esta perspectiva de la máxima efectividad del Derecho europeo, no es de extrañar que se haya en ocasiones propugnado la tipificación expresa de una causa de nulidad de pleno derecho consistente en la vulneración del Derecho europeo. Esto supondría establecer un vicio de validez en función

28 Martínez Andrés, de 14 de septiembre de 2016 (C-184/15 y C-197/15), donde una de las cuestiones que planteaba el Tribunal a quo afectaba específicamente a este principio de efectividad, pues hacía referencia a la necesidad de que los interesados (funcionarios interinos y estatutarios de los Servicios de Salud) tuvieran que interponer un nuevo recurso e iniciar un nuevo proceso para obtener la reparación del daño, diferente al proceso en el que se declaró abusivo el encadenamiento de nombramientos temporales. El Tribunal de Justicia considerará que «la obligación que incumbe al trabajador con contrato de duración determinada de ejercitar una nueva acción, en su caso ante un tribunal diferente, para determinar la sanción apropiada cuando una autoridad judicial ha declarado la existencia de utilización abusiva de sucesivos contratos de trabajo de duración determinada no muestra ser conforme con el principio de efectividad, en la medida en que de ella se derivan necesariamente para dicho trabajador inconvenientes procesales, en forma, en particular, de costes, de duración y de normativa de representación procesal». En consecuencia, «lo dispuesto en el Acuerdo marco sobre el trabajo de duración determinada, que figura en el anexo a la Directiva 1999/70, en relación con el principio de efectividad, debe interpretarse en el sentido de que se opone a normas procesales nacionales que obligan al trabajador con contrato de duración determinada a ejercitar una nueva acción para que se determine la sanción apropiada cuando una autoridad judicial ha declarado la existencia de utilización abusiva de sucesivos contratos de duración determinada, en la medida en que de ellas se derivan para dicho trabajador inconvenientes procesales en forma, en particular, de costes, de duración y de normativa de representación procesal, que pueden hacer excesivamente difícil el ejercicio de los derechos que le confiere el ordenamiento jurídico de la Unión»

29 Prezes Urzędu, 13 octubre 2016 (C-231/15).

30 Así, la limitación de vicios de procedimiento a la completa exclusión de éste y no a los meros defectos del mismo, privaría de efecto útil a la Directiva (2011/92/UE) del Parlamento Europeo y del Consejo, de 13 de diciembre de 2011, relativa a la evaluación de las repercusiones de determinados proyectos públicos y privados sobre el medio ambiente [Comisión v. Alemania, 15 octubre 2015 (C-137/14)].

31 Martínez Andrés, 14 septiembre 2016 (C-184/15 y C-197/15).

32 Sobre el tema, FUENTETAJA, J. (2018): Derecho europeo y Función Pública, Civitas.

33 Sendas Sentencias de 29 de septiembre de 2018 del Tribunal Supremo (recursos números 1305/2017 y 785/2017) descartan explícitamente el alcance del principio de efectividad hasta el extremo de desconocer los límites del Derecho y la jurisprudencia interna. 
del origen formal de la norma ${ }^{34}$ en lugar de las características propias del acto -sean formales, sean sustantivas-, que es el criterio que sigue nuestro Ordenamiento ${ }^{35}$, lo cual puede considerarse que «perturbaría la teoría misma sobre la invalidez de los actos administrativos», en palabras del Consejo de Estado ${ }^{36}$. Probablemente en tales propuestas late más la idea de facilitar la revisión de oficio del acto contrario al Derecho europe ${ }^{37}$ que la consideración de la gravedad en sí de la vulneración de éste, perspectiva de revisión que en todo caso siempre constituye un peligro para la interpretación de los supuestos de nulidad en la medida en que facilita las potestades de control de la Administración frente al proceso de lesividad.

Sea como fuere, teniendo en cuenta, por un lado, que el Derecho europeo no impone una categorización jurídica determinada de su vulneración y, por otro, que sólo exige de los Estados que sus sistemas garanticen que la legalidad europea violentada es adecuada y oportunamente restablecida, la problemática del acto administrativo nacional contrario al Derecho europeo no afecte tanto a la categorización de la invalidez como a las posibilidades de revisión de aquel y los efectos de ésta.

\section{Efectividad y procedimientos de revisión}

En efecto, al Derecho europeo lo que le preocupa es que los Estados, en el ámbito de la ejecución indirecta, establezcan procedimientos que garanticen el restablecimiento de la legalidad europea vulnerada por una actuación administrativa. La regulación de esos procedimientos puede incluir previsiones que limiten o incluso impidan la revisión de los actos administrativos nacionales. Así, por ejemplo, la imposición de plazos perentorios para interponer recursos ${ }^{38}$ o ejercer potestades de revisión de actos anulables favorables sin duda dificultan -en aras, ciertamente, de la seguridad jurídica- la posibilidad de invalidar actos en vía administrativa o judicial, aun cuando la constatación de su ilegalidad europea es manifiesta.

Es el caso, en particular, de las contradicciones indirectas, cuando de una Sentencia del Tribunal de Justicia de la Unión Europea se deriva que la norma de la que el acto administrativo interno es aplicación es contraria al Derecho europeo. La eventual invalidez de dicho acto puede verse internamente impedida en el caso de situaciones jurídicas consolidadas que el Ordenamiento interno pretende preservar pese a su ilegalidad. Es el caso de los actos firmes y de los confirmados por sentencia judicial y que se beneficiarían de la fuerza de cosa juzgada.

El Derecho europeo, en principio, respeta los Ordenamientos internos, también en sus opciones de seguridad jurídica que impiden la revisión de los actos internos que, no obstante, son contrarios al Derecho europeo. Sin embargo, en determinadas circunstancias, el Tribunal de Justicia ha considerado que las exigencias de legalidad europea se deben imponer sobre las técnicas de preservación de la seguridad jurídica interna.

\subsection{Obligación de revisión de actos firmes conforme a procedimientos internos}

En la sentencia Kühne \& Heitz ${ }^{39}$ el Tribunal de Justicia sentaría una doctrina que, con apenas modificaciones posteriores, establece las exigencias del Derecho europeo sobre la revisión de actos administrativos internos, si bien formularía una obligación de revisión sujetándola a unas «circunstancias» o «condiciones» que limitaban sobremanera su alcance.

Estas condiciones cumulativas serían precisadas posteriormente por el Tribunal de Justicia en diferentes sentencias que permiten entender el alcance y el fundamento de la revisión de actos firmes nacionales

${ }^{34}$ ARZOZ SANTISTEBAN, X. (2013): La revisión de actos administrativos nacionales en Derecho Administrativo Europeo. En particular la recuperación de ayudas de Estado ilegales, Pamplona: Civitas-Thomson Reuters, pág. 102.

${ }^{35}$ PARADA, R. (2018): Derecho Administrativo II. Régimen jurídico de la actividad administrativa, $24 .{ }^{a}$ ed., EDIASA, págs. 94-121.

36 CONSEJO DE ESTADO (2008): Informe sobre la inserción del Derecho europeo en el Ordenamiento español. Comentarios a este relevante informe, ORDOÑEZ SOLIS, D. (2008): "Derecho, administración e integración de España en la Unión Europea bajo el prisma del Consejo de Estado" en Revista española de derecho europeo, núm. 27, págs. 235-279, para quien bastaría que se asumiese que «el control jurisdiccional y también el control administrativo de los actos de las Administraciones debe incluir como motivo de nulidad la "infracción de normas de Derecho comunitario europeo"».

37 FERNÁNDEZ TORRES, J. R. (1991): "Revisión de oficio de los actos administrativos dictados con infracción del Derecho comunitario" en Revista de Administración Pública, núm. 125, págs. 281-316.

${ }_{38}$ Rosado Santana, 8 septiembre 2011 (C-177/10), núm. 96, que versaba sobre el plazo de dos meses para la interposición del recurso de alzada regulado por entonces en la Ley 30/1992 de Régimen Jurídico de las Administraciones Públicas y del Procedimiento Administrativo Común.

${ }^{39}$ Kühne \& Heitz, 13 enero 2004 (C-453/00). 
cuya vulneración del Derecho europeo se evidencia a posteriori por los Tribunales europeos. Tales condiciones son:

1. el Derecho nacional establece procedimientos que permiten a la Administración reconsiderar una resolución firme;

2. la resolución controvertida ha adquirido firmeza a raíz de una sentencia de un órgano jurisdiccional nacional que resuelve en última instancia; por tanto, no basta que haya adquirido firmeza por no haber sido recurrida en alguna instancia, administrativa o judicial, pues el interesado tiene que haber agotado todas las posibilidades de recurso interno que su Derecho interno le permitía ${ }^{40}$.

3. dicha sentencia está basada en una interpretación del Derecho comunitario que, a la vista de una jurisprudencia del Tribunal de Justicia posterior a ella, es errónea y que se ha adoptado sin someter la cuestión ante el Tribunal de Justicia, con carácter prejudicial;

4. el interesado se ha dirigido al órgano administrativo inmediatamente después de haber tenido conocimiento de dicha jurisprudencia; esta imprecisión temporal remite nuevamente al Derecho nacional para el ejercicio de acciones, con el consiguiente respeto de los principios de equivalencia $y$, particularmente, de efectividad, desde cuyo prisma podrá enjuiciar la razonabilidad del plazo establecido por el Derecho interno ${ }^{41}$.

El fundamento de la obligación de revisión se habría identificado con la ausencia de planteamiento de la cuestión prejudicial cuando, en principio, el órgano jurisdiccional estaba obligado a ello por resolver en última instancia, siendo así que a posteriori se reveló errónea su consideración de que el Derecho europeo aplicable no planteaba dudas de interpretación. De esta omisión del órgano jurisdiccional se derivarían no sólo el error objetivo en la interpretación del Derecho europeo sino también el perjuicio subjetivo del interesado al no poder ejercer los derechos que le reconoce el Ordenamiento europeo ${ }^{42}$.

Aquí radicaría la singularidad del alcance de la jurisprudencia Kühne: los Estados deben activar sus procedimientos de revisión de actos firmes que se manifiestan posteriormente contrarios al Derecho europeo porque no actuaron correctamente al no plantear la cuestión prejudicial que hubiese evitado en su día la vulneración del Derecho europeo.

Sin embargo, el punto débil de la construcción del Tribunal de Justicia radica en la deferencia que hace al Derecho nacional en cuanto es éste el que debe prever el procedimiento de revisión. De no existir tal previsión en el ámbito interno, la revisión no procede. Esta concesión al principio de autonomía procedimental de los Estados hay que entenderla como un intento de conciliar la revisión de actos firmes que impondría la legalidad y la eficacia del Derecho europeo con la seguridad jurídica de las situaciones jurídicas creadas en virtud de aquellos. En última instancia, la efectividad del Derecho europeo queda condicionada al Derecho procedimental nacional. La superación de esta condición, sin embargo, ha sido apuntada también por el Tribunal de Justicia.

\subsection{Derecho a un procedimiento de revisión por vulneración del Derecho europeo}

En el asunto Byankov ${ }^{43}$, relativo a una doble prohibición de salida del territorio y de expedición de pasaporte que ni siquiera fue recurrida por el interesado en su momento, el Tribunal de Justicia examina si la regulación búlgara del procedimiento administrativo para revocar actos firmes no permite salvaguardar los derechos que el Derecho de la Unión confiere, exigiendo el reconocimiento de la existencia de un deber que recaería sobre la Administración que consistiría en analizar y, en su caso, revocar un acto administrativo

40 I-21 y Arcor, 19 septiembre 2006 (C-392/04 y C-422/04), núm. 53; Byankov, 4 octubre 2012 (C-249/11), núm. 51.

41 Kempter, 12 febrero 2008 (C-2/06), núm. 59.

42 En palabras del Abogado General BOLT, «en presencia de una interpretación errónea del Derecho comunitario hecha por un órgano jurisdiccional nacional cuyas resoluciones no pueden ser objeto de recurso jurisdiccional de Derecho interno y de un incumplimiento por parte de dicho órgano jurisdiccional de su obligación de presentar una petición de decisión prejudicial, prevista en el artículo $234 \mathrm{CE}$, párrafo tercero, el artículo $10 \mathrm{CE}$ tiene el efecto de transformar la facultad otorgada a un órgano administrativo por su Derecho nacional en una obligación de revisar una resolución administrativa firme contraria al Derecho comunitario, revocándola o no, según resulte de dicha revisión. La solución resultante de la sentencia Kühne \& Heitz, antes citada, permite de este modo paliar, a través del artículo $10 \mathrm{CE}$, los efectos negativos que provoca la ausencia de remisión prejudicial en la situación prevista en el artículo 234 CE, párrafo tercero, ofreciendo a los justiciables que han hecho uso de las vías de recurso establecidas en su Derecho interno una nueva posibilidad de invocar los derechos que les confiere el Derecho comunitario»: Kempter, 12 febrero 2008 (C-2/06), núms. 80-82.

43 Byankov, 4 octubre 2012 (C-249/11). 
contrario al Derecho europeo, aunque fuera firme. Y lo hará a partir de los principios de cooperación leal y de efectividad.

Al amparo del primero, el Tribunal de Justicia declara sin ambages «que la concurrencia de circunstancias particulares puede, en virtud del principio de cooperación leal establecido en el artículo 4 TUE, apartado 3 , determinar que un órgano administrativo nacional quede obligado a revisar una resolución administrativa que ha adquirido firmeza para, en particular, tomar en consideración la interpretación, realizada posteriormente por el Tribunal de Justicia, de una disposición de Derecho de la Unión pertinente».

$Y$ aunque menciona la saga de pronunciamientos anteriores que han impuesto la revisión de actos administrativos internos por encima de su firmeza (Kühne \& Heitz; i-21 Germany y Arcor; Kempter) o de la fuerza de cosa juzgada de la que se beneficiaban (Lucchini ${ }^{44}$, Olimpiclub $\left.{ }^{45}\right)$, ponderando «las particularidades de las situaciones y de los intereses en cuestión para encontrar un equilibrio entre la exigencia de seguridad jurídica y la exigencia de legalidad a la luz del Derecho de la Unión» (núm. 77), lo trascendente de la sentencia Byankov es que el Tribunal de Justicia se va a liberar de esas "particularidades de la situaciones» para reconocer directamente la obligación de las Administraciones nacionales de revisar actos nacionales cuya ilegalidad europea es clara e, indirectamente, el derecho de los afectados a solicitar esa revisión.

Si el principio de cooperación leal le sirvió al Tribunal para sentar las bases generales de la revisión de actos firmes contrarios al Derecho europeo, recurrirá, por su parte, al principio de efectividad para verificar la adecuación del procedimiento administrativo nacional a las necesidades ejecutivas del Derecho europeo, pero lo hará, como advertíamos, desde parámetros generales y abstractos y no tanto desde las circunstancias fácticas y jurídicas del caso. De hecho se observa claramente el contraste entre la aproximación del Abogado General y la que posteriormente llevará a cabo el propio Tribunal, a pesar de llegar a la misma conclusión de contradicción con el principio de efectividad de la regulación procedimental nacional: mientras aquel disecciona el breve plazo y la limitada legitimación activa (que excluye al destinatario del acto) para incoar el procedimiento de revisión ${ }^{46}$, el Tribunal de Justicia considera que la ausencia de procedimientos que permitan revisar prohibiciones definitivas y firmes de abandonar el territorio de un Estado, cuya ilegalidad ha sido constatada por el Tribunal de Justicia, abocan a la «negación misma de la libertad de circulación y de residencia en el territorio de los Estados miembros conferida por el estatuto del ciudadano de la Unión» (núm. 79).

En consecuencia, «una normativa nacional como la descrita en la resolución de remisión, en cuanto impide a ciudadanos de la Unión hacer valer su derecho a la libre circulación y a la libre residencia que les confiere el artículo 21 TFUE frente a prohibiciones territoriales absolutas adoptadas por una duración ilimitada, y a los órganos administrativos extraer las correspondientes consecuencias de un pronunciamiento jurisprudencial del Tribunal de Justicia que confirma el carácter ilícito, a la luz del Derecho de la Unión, de tal prohibición, no puede estar razonablemente justificada por el principio de seguridad jurídica y, por tanto, debe considerarse, en esa medida, contraria al principio de efectividad y al artículo 4 TUE, apartado 3» (núm. 81).

Por tanto, del derecho que el Ordenamiento europeo confiere a los ciudadanos se derivaría la obligación para los Estados de revisar cualquier vulneración producida por un acto administrativo, con independencia de que sea firme y con independencia también de cuál sea la causa de esta firmeza.

De esta manera, el Tribunal se libera definitivamente de la deferencia nacional que hacía a la necesidad de que el Derecho nacional hubiese previsto vías de procedimiento de revisión. De haber seguido la estela que le trazaba el Abogado General, se podía haber limitado a considerar que tanto el plazo de un mes como

44 Lucchini, 18 julio 2007 (C-119/05), Rec., pág. I-6228, en la que el Tribunal de Justicia fallará de forma categórica que «el Derecho comunitario se opone a la aplicación de una disposición de Derecho nacional que pretende consagrar el principio de autoridad de la cosa juzgada [...] cuando su aplicación constituye un obstáculo para la recuperación de una ayuda de Estado concedida contraviniendo el Derecho comunitario, y cuya incompatibilidad con el mercado común ha sido declarada por una decisión firme de la Comisión de las Comunidades Europeas». Un excelente comentario a esta sentencia en MARTíN RODRÍGUEZ, P. J. (2007): "Res judicata proveritate habetur c. primacía del derecho comunitario: ¿un combate por librar? (A propósito de la Sentencia del Tribunal de Justicia de 18 de julio de 2007, asunto C-119/05, Lucchini)", en Revista española de derecho europeo, núm. 24, págs. 521-557.

45 Olimpiclub, 3 septiembre 2009 (C-2/08), núm. 29: «Por consiguiente, esta aplicación del principio de fuerza de cosa juzgada tendría como consecuencia que en el supuesto de que la resolución judicial definitiva se basare en una interpretación de normas comunitarias relativas a prácticas abusivas en materia de IVA contraria al Derecho comunitario, la aplicación incorrecta de estas normas se reproduciría en cada nuevo ejercicio fiscal, sin que fuera posible corregir esta interpretación errónea. En estas circunstancias, debe declararse que obstáculos de tal envergadura a la aplicación efectiva de las normas comunitarias en materia de IVA no pueden estar razonablemente justificados por el principio de seguridad jurídica y, por tanto, deben considerarse contrarios al principio de efectividad» (núm. 30).

${ }^{46}$ Conclusiones del Abogado General MENGOZZI (núms. 57-58). 
la exclusión del destinatario de entre los legitimados para instar la revocación del acto contrario al Derecho europeo no superaban el «test de efectividad» por cuanto hacían imposible hacer valer el derecho de la libre circulación previsto en el Tratado europeo. Sin embargo, el Tribunal de Justicia afirmará explícitamente que el Estado tiene la obligación de establecer un procedimiento de revisión de actos administrativos que sean contrarios al Derecho europeo cuando vulneren derechos atribuidos por el Ordenamiento jurídico europeo. Lo que correlativamente implica el derecho de los titulares de tales derechos vulnerados a solicitar la revisión de los actos, con independencia de la firmeza de los mismos.

El problema es la identificación de la "circunstancias particulares» ${ }^{47}$ que determinarían la obligación de las Administraciones nacionales de revisar actos firmes (incluso por no haber sido recurridos) y el correlativo derecho de los interesados a solicitar esa revisión. Es algo que el Tribunal de Justicia aún no ha definido y probablmente lo vaya haciendo a base de sentencias cuando considere tanto el carácter manifiesto como la gravedad de la vulneración del Derecho europeo.

\section{Efectividad y efectos de la revisión}

Si ya en materia de revisión el Derecho europeo tiene una incidencia relevante al relativizar técnicas basadas en la seguridad jurídica (como la firmeza de los actos o la fuerza de cosa juzgada de las sentencias) cuando concurren circunstancias particulares en su vulneración por actos administrativos nacionales dictados en el marco de la ejecución directa, también en relación con los efectos de la eventual invalidez de dichos actos podemos observar unas exigencias particulares.

En efecto, el principio de legalidad europeo, articulado respecto a los Ordenamientos nacionales vía principios de primacía y de eficacia directa, impone que el restablecimiento de la dicha legalidad vulnerada se produzca con efectos no de la declaración de ésta sino desde que la norma europea infringida fue dictada. Esta eficacia ex tunc de la invalidez de los actos administrativos nacionales contrarios al Derecho europeo sería consecuencia de las exigencias inherentes al principio de legalidad europea, cuyas excepciones sólo pueden ser amparadas por el propio Ordenamiento europeo, no por el nacional.

Ciertamente, el Derecho europeo no ha regulado de manera sistemática y exhaustiva las excepciones al principio de legalidad basadas en el principio de seguridad jurídica, por lo que -siempre en virtud de la remisión que implica el principio de autonomía de los Estados en la ejecución del Derecho europeo- asume, en principio, las opciones internas de mantenimiento de situaciones creadas al amparo de normas o actos posteriormente declarados inválidos. Sin embargo, una vez constatada la ilegalidad europea de un acto nacional, el Ordenamiento europeo exige que las consecuencias de aquella ilegalidad se vean removidas desde que la norma vulnerada fue dictada.

Esta eficacia ex tunc sería una exigencia inherente a la propia institución de la invalidez ${ }^{48}$, que en el caso del Derecho europeo se manifiesta no sólo en el ámbito del Derecho de la Administración europea (donde la invalidez es siempre ex tunc ${ }^{49}$ ) como en el del régimen jurídico de la ejecución por los Estados del Derecho europeo.

En efecto, desde una perspectiva estrictamente europea, el principio de legalidad impondría que toda vulneración del Derecho europeo se vea remediada y las consecuencias que resuelven dicha vulneración se extiendan durante todo el tiempo que ésta se produjo. Esa misma exigencia del principio de legalidad europea la proyectaría el Tribunal de Justicia sobre la anulación de actos nacionales contrarios al Derecho europeo. La concepción que tiene el Tribunal de Justicia del principio de legalidad europea, articulado en relación con los Estados a través de los principios de eficacia directa y de primacía, le llevaría a considerar que la contradicción entre el acto nacional -normativo o singular- y el acto europeo -normativo o singular- debe conducir siempre a que las consecuencias jurídicas en forma de invalidez -aunque también de ineficacia- que se establezcan lo sean en toda su extensión temporal, para impedir que se mantengan con carácter general situaciones jurídicas creadas como consecuencia de vulneraciones del Derecho europeo.

\footnotetext{
47 Incyte, 20 diciembre 2017 (C-492/16)

48 Las reflexiones doctrinales recientes sobre la materia destacan precisamente esta dimensión institucional a la hora de determinar la eficacia temporal de la invalidez, negando así la simplista división dicotómica entre los efectos temporales de la nulidad de pleno de derecho y de la anulabilidad. Por todos, REBOLLO, M. (2016): "La invalidez del acto administrativo", en REBOLLO, M., CARBONELL, E. (coords.), Derecho Administrativo. Tomo II: Régimen jurídico básico y control de la Administración, Tecnos, pág. 108 y ss; CANO, T. (2017): "El laberinto de la invalidez. Algunas pistas para no perderse", en El alcance de la invalidez de la actuación administrativa: Actas del XII Congreso de la Asociación Española de Profesores de Derecho Administrativo, págs. 57-116.

49 FUENTETAJA, J. (2016): Derecho Administrativo Europeo, 3. ${ }^{a}$ ed., Civitas, págs. 313-334.
} 
Esto se puede deducir de la jurisprudencia del Tribunal de Justicia cuando señala que, con carácter excepcional y en virtud del principio de seguridad jurídica, únicamente el propio Tribunal de Justicia puede «suspender provisionalmente el efecto de exclusión que ejerce una norma de la Unión directamente aplicable sobre el Derecho nacional contrario a ella» ${ }^{50}$, lo que abarcaría el mantenimiento de los efectos de una disposición nacional contraria al Derecho con efectos prospectivos ${ }^{51}$, pero también retroactivos, para no cuestionar los actos dictados al amparo de la norma contraria al Derecho europeo si ello fuese contraproducente para la propia efectividad de éste, matizando los principios de legalidad europea y de primacía.

En los asuntos Inter-Environnement Wallonie y Terre wallonne ${ }^{52}$ y Association France Nature Environnement ${ }^{53}$, el Derecho procesal belga y francés, respectivamente, permitían a los jueces modular la eficacia retroactiva de la anulación de normas, permitiendo discrecionalmente señalar qué situaciones jurídicas se podían considerar definitivas y, por tanto, no afectadas por la anulación. El Tribunal de Justicia advierte que -en caso de normas anuladas por vulnerar Derecho europeo- esa potestad discrecional de señalar el mantenimiento de efectos definitivos por aplicación de dichas normas implicaría privar de eficacia a las normas europeas vulneradas, por lo que «puede autorizarse excepcionalmente a un órgano jurisdiccional nacional, habida cuenta de la existencia de una consideración imperiosa relacionada con la protección del medio ambiente, a que aplique la disposición nacional que le habilita para mantener determinados efectos de un acto nacional anulado, siempre que se cumplan determinados requisitos» ${ }^{54}$.

Estos requisitos son: primero, que la disposición de Derecho nacional impugnada constituya una medida de transposición adecuada del Derecho de la Unión en materia de protección del medio ambiente; segundo, que la adopción y la entrada en vigor de una nueva disposición de Derecho nacional no permitan evitar los efectos perjudiciales en el medio ambiente que se derivan de la anulación de la disposición de Derecho nacional impugnada; tercero, que la anulación de esta última tenga como consecuencia crear un vacío legal por lo que respecta a la transposición del Derecho de la Unión en materia de protección del medio ambiente que resulte más perjudicial para el medio ambiente en el sentido de que dicha anulación supondría una menor protección, y vulneraría incluso el objetivo esencial del Derecho de la Unión; y cuarto, que el mantenimiento excepcional de los efectos de la disposición de Derecho nacional impugnada sólo cubra el tiempo estrictamente necesario para que se adopten las medidas que subsanen la irregularidad declarada» ${ }^{55}$.

Por tanto, la voluntad del Tribunal de Justicia es que, en principio, sólo él pueda «reconocer a un órgano jurisdiccional nacional, caso por caso y con carácter excepcional, la facultad de determinar los efectos de la anulación de una disposición nacional juzgada incompatible con el Derecho de la Unión» ${ }^{56}$.

Es decir, en principio las consecuencias jurídicas que se prevean como respuestas a la vulneración del Derecho europeo deben remover cualquier efecto temporal pasado que se derive de dicha vulneración, atribuyendo, por tanto, eficacia ex tunc a la anulación de actos contrarios al Derecho europeo. Consecuencia de ello sería la inadecuación de la eficacia ex nunc de los efectos de la invalidez de los actos administrativos contrarios al Derecho europeo.

Todo ello tiene una particular importancia en el marco de las contradicciones indirectas, en particular cuando la contradicción directa lo es de la norma interna con la norma europea y la ilegalidad de aquella afecta a los numerosos actos administrativos dictados a su amparo. Esta contradicción de la norma interna puede ser apreciada directamente al proceder a su aplicación, pero normalmente mediará un pronunciamiento expreso del Tribunal de Justicia -en particular, a través de cuestiones de interpretación y de recursos por incumplimiento- en el que declare la incompatibilidad de la norma interna con el Derecho europeo. A partir de la sentencia del Tribunal de Justicia, tanto Jueces y Tribunales como Administraciones públicas deben extraer las consecuencias que se derivan de aquella, primero anulando -si pueden-o inaplicando -en

50 «En efecto, si los órganos jurisdiccionales estuvieran facultados para otorgar primacía a las normas nacionales contrarias al Derecho de la Unión, aunque fuera con carácter provisional, se estaría actuando en menoscabo de la aplicación uniforme de este último ordenamiento»: Association France Nature Environnement, 28 julio 2016 (C379/15), núm. 33.

51 Winner Wetten, 8 septiembre 2010 (C409/06), núm. 67.

52 Inter-Environnement Wallonie y Terre wallonne, 28 febrero 2012 (C41/11).

53 Association France Nature Environnement, 28 julio 2016 (C379/15).

54 Association France Nature Environnement, 28 julio 2016 (C379/15), núm. 33.

55 Association France Nature Environnement, 28 julio 2016 (C379/15), núm. 43.

56 Association France Nature Environnement, 28 julio 2016 (C379/15), núm. 34. Ello sin perjuicio de su doctrina del acto claro que le exonere de plantar la cuestión prejudicial, pero en tal caso «puesto que el principio de primacía del Derecho de la Unión puede resultar vulnerado a consecuencia del ejercicio de esa facultad excepcional, sólo cuando el antedicho órgano jurisdiccional nacional esté convencido de que el ejercicio de tal prerrogativa no plantea ninguna duda razonable cesará la obligación de someter la cuestión prejudicial al Tribunal de Justicia. Además, esa ausencia de duda razonable debe haber resultado probada de forma fehaciente» (núm. 52). 
todo caso- la norma declarada incompatible con el Derecho europeo y, segundo, trasladando los efectos de esta anulación o inaplicación a los actos administrativos que han sido dictados al amparo de esa norma.

Y ello teniendo en cuenta que las sentencias del Tribunal de Justicia, al interpretar una norma europea y declarar incompatible con ella la norma nacional, producen efectos no desde la fecha de la sentencia sino desde la fecha en que fue aprobada la norma europea que había sido incumplida por la norma nacional, con independencia de que la sentencia se pronuncie como consecuencia de un recurso por incumplimiento o del planteamiento de una cuestión prejudicial ${ }^{57}$. Así, en relación con esta última, el Tribunal de Justicia señala con firmeza que la interpretación que da el Tribunal de Justicia de una norma de Derecho europeo «aclara y especifica, cuando es necesario, el significado y el alcance de dicha norma, tal como ésta debe o habría debido entenderse y aplicarse desde el momento de su entrada en vigor ${ }^{58}$.

Estos efectos retroactivos obligarían, por tanto, a revisar las situaciones jurídicas creadas al amparo de la norma nacional, por cuanto constituirían igualmente aplicaciones contrarias al Derecho europeo. En efecto, «la norma así interpretada puede y debe ser aplicada por el Juez incluso a relaciones jurídicas nacidas y constituidas antes de la sentencia que resuelva sobre la petición de interpretación, siempre y cuando, por otra parte, se reúnan los requisitos necesarios para someter a los órganos jurisdiccionales competentes un litigio relativo a la aplicación de dicha norma» ${ }^{59}$.

\section{CONCLUSIONES}

El Derecho europeo ha limitado la propia remisión que realiza a los Derechos Administrativos nacionales de regular la ejecución indirecta del Derecho europeo por las Administraciones nacionales. Y lo hace también verificando si el régimen jurídico de la invalidez y de la revisión nacional se aplica por igual a las vulneraciones del Derecho europeo por actos nacionales (principio de equivalencia) y no impide o dificultad que la legalidad europea despliegue sus efectos (principio de efectividad).

A partir de aquí, la tensión estructural que subyace en todo sistema de invalidez y revisión entre los principios de legalidad y de seguridad jurídica presenta complejidades añadidas por cuanto la legalidad europea propende a no verse excepcionada por la seguridad jurídica interna. Sin embargo, a falta de un régimen consistente europeo que regule la ejecución que hacen los Estados del Derecho europeo, las soluciones alcanzadas por el Tribunal de Justicia para relativizar las técnicas jurídicas internas que articulan esa seguridad jurídica (en particular, la firmeza de los actos administrativos y las potestades de conservación de situaciones creadas al amparo de actos contrarios al Derecho europeo) no dejan de resultar insatisfactorias por su imprecisión. Si el Derecho europeo no quiere o no puede regular positivamente un sistema procedimental para que los Estados garanticen la legalidad europea, debe aclarar cuándo se puede sacrificar la seguridad jurídica nacional en aras de la legalidad europea, precisando, en particular, cuáles son esas «circunstancias particulares» que obligan a las Administraciones nacionales a revisar actos nacionales por vulnerar el Derecho europeo, incluso sin procedimiento interno previo.

57 Esta eficacia ex tunc de las Sentencias del Tribunal de Justicia de la Unión Europea ha sido acogida por nuestro Tribunal Constitucional, reconduciéndola al derecho a la tutela judicial efectiva sin indefensión (art. 24.1 CE), en su dimensión de derecho a una resolución judicial fundada en Derecho, pues lo contrario supondría aplicar leyes contrarias al Derecho europeo: «La declaración por el Tribunal de Justicia de la Unión Europea de que esa norma es contraria al Derecho comunitario impone a los órganos jurisdiccionales españoles (incluidos, desde luego, este Tribunal) la obligación de inaplicarla, extrayendo de esta operación jurídica las consecuencias oportunas»: SSTC 145/2012, de 2 de junio y 232/2015, de 5 de noviembre. Al respecto, el excelente trabajo de ARROYO, L. (2016): Empatía constitucional. Derecho de la Unión Europea y Constitución Española, Marcial Pons, págs. 73-118.

58 Amministrazione delle finanze dello Stato v. Denkavit italiana, 27 marzo 1980 (61/79), Rec. pág. 1.205 , núm. 15.

59 Amministrazione delle finanze dello Stato v. Denkavit italiana, 27 marzo 1980 (61/79), Rec. pág. 1.205, núm. 15. 